\title{
IMPACT OF MOTIVATION ON THE PERFORMANCE OF EMPLOYEES:A CASE STUDY OF BANKING INDUSTRY OF PAKISTAN
}

\author{
NajmaShaikh \\ Assistant Professor- Deptt:of Economics, University of Sindh jamshoro \\ Aisha Bashir Shah \\ Assistant Professor-IBA-University of Sindh jamshoro \\ MsAlbeenaMirza \\ Assistant Professor ,Department of Economics University of Sindh Jamshoro

\section{Dr.Muhammad Ali Bhatti} \\ Assistant Professor IBA-Sukkur
}

\begin{abstract}
The current research investigates the impact of motivation on the performance of employees: A Case study of banking industry of Pakistan. Data were collected from 200 respondents from Branch Managers to operation Managers five Banks UBL, HBL, ABL, Askari and Alfalah Bank limited. It was revealed that motivation has positive impact on the employee performance. It was further revealed that motivation is the only tool through you will satisfy your team. It was further revealed that most of the branch managers were not happy with long office hours from 9.am-9.pm. Motivation is the only factor that boost up their performance.
\end{abstract}

Key Words: Motivation, Performance, Employees, Banking Industry. Introduction:

Motivation is the term that most of the organization are using to satisfy the needs and wants of the employees. Better execution of representative's is obligatory for the achievement of organization as the survival and accomplishment of any establishment is depend upon the motivation, modernization and devotion of the workers. What's more, propelled educators locate the distinctive techniques and new specialized strategies to instruct the understudies. What's more, consequence of this quality training, numerous specialists, designers, patches, and great representatives come into society.

\section{Literature Review}

Inspiration is an inward procedure which guides any one to carry on especially. It is a power that supports eagerness and it varies relying upon circumstance (Rogers, 1996). It is the advancement of a desire in a representative to finish an assignment to the best capacity in view of that individual's own particular activity (Rudolf and Kleiner, 1989). It is the endeavor to achieve top execution consistently, to appreciate the persistent test of enhancing results, to really think about their associates and their organization, and to keep up positive results (Evenson, 2003, p.21). It is the eagerness to apply large amounts of exertion toward authoritative objectives, adapted by the individual's capacity to fulfill some individual need (Robbins, 1993 as refered to in Lu, 1999, p.63). Rousing is the capacity to teach the workers with a solidarity of reason and to keep up a proceeding, concordant relationship among all individuals. It is a power which influences and advances an energy of each worker to participate with each individual from the group. Through inspiration the authoritative atmosphere gets to be symphonious to all the work bunches and the organization in general gets profited. Borcherding and Oglesby (1975) expressed that occupation disappointment can be one variable that will build costs, produce time delays and by and large decrease profitability on most sorts of activities. One way that administration can build profitability is by how it impacts laborer's state of mind, which is a noteworthy component in specialist inspiration and decide the amount of work will be refined.

\section{Hypotheses of Motivation}

Frederick W. Taylor's logical administration Toward the end of the nineteenth century, Frederick W. Taylor presented the use of investigative standards to the administration of work and laborers which is known as exploratory administration,. Taylor proposed that every employment be separated into its different undertakings. Supervisors ought to decide the most ideal approach to execute every errand and the level of creation that ought not out of the ordinary. The best individual for every employment will be chosen and prepared. Taylor trusted that individuals work just to acquire cash and in this way cash ought to be coordinated to yield.

\section{Hawthorne Studies}

Elton Mayo directed an examination somewhere around 1927 and 1932, which is known as the Hawthorne Studies, to discover the impacts of the workplace on specialist profitability. The main arrangement of tests utilized distinctive levels of lighting as a part of the plant for one gathering, and a steady level of light in the control bunch. Be that as it may, the outcome was shocking as efficiency expanded in both gatherings. At that point Mayo utilized the piece-rate framework with gatherings of specialists, instead of people and found that creation stayed consistent. It was inferred that human

\footnotetext{
$\mathbf{2 9 6 0} \mid \mathrm{P}$ a g e 
variables were in charge of the outcomes. In the lighting analyze the individuals felt essential as they were included in a gathering. In the second examination, bunches kept up a relentless pace in light of a craving for social acknowledgment. These conclusions produce that for better execution laborers ought to be fulfilled.

\section{Maslow's Hierarchy of Needs}

Abraham Maslow initially exhibited the five-level progression of requirements in 1942 to a psychoanalytic culture and distributed it in 1954 in Motivation and Personality (New York: Harper and Row). He recognized that the most fundamental need develops first and the most refined need last. He proposed that individuals begin on the base and put endeavors to go up to necessities chain of command. When one need is satisfied, it loses its quality and the following level of necessities is actuated. A fulfilled need is longer a spark. The most intense worker help is the need which has not been fulfilled. As indicated by Maslow, physiological necessities are the things we require for survival, similar to, nourishment, garments, haven, and rest. In corporate world, sufficient wages speak to such kind of necessities. Next level is of wellbeing needs, which are essential for physical and enthusiastic security. Through professional stability, medical coverage, retirement advantages, and safe workplaces, these necessities are fulfilled. Climbing to the third level is the social need, where individuals look for adoration, fondness and having a place. Connections in the workplace and in the casual association, and in addition in informal communities with family and companions outside the association are great case of social needs. Next level is the regard need, where we encourage for admiration, acknowledgment, achievement and worth. The administration can satisfy such needs by coordinating the expertise and capacity of the representative to the occupation, by demonstrating laborers that their work is welcomed. At long last, the self-realization needs, which are the cravings to develop and create up to ones fullest potential.

\section{Alderfer's ERG model}

Clayton Alderfer recognized three classes of requirements: presence needs, relatedness needs and development needs. Presence needs are the wishes for physical prosperity. Relatedness needs are the inclinations to palatably identifying with others by setting up and keeping up interpersonal connections. Development needs are the cravings to self improvement, innovativeness, development, and fitness. As per Alderfer, one might be spurred by requirements on a few levels in the meantime and when people are disappointed in meeting one level needs, they may focus on the following lower level needs.

\section{McClelland's Needs Theory of Motivation}

David C. McClelland separated inspiration into requirements for force, connection, and accomplishment. Individuals having requirement for Power look for positions of initiative. They generally attempt to control or rule others. They get a kick out of the chance to practice their impacting power. They are intense, pugnacious, resolved, and candid. Association roused individuals typically get delight from being adored and associated with others. Accomplishment spurred individuals have an escalated longing for achieving objectives and achievement. They need to control the circumstances in which they are included. They go for broke and set sensible targets. They need to be tested and jump at the chance to dissect issues.

\section{Information Collection Methodology}

Information were gathered from 200 respondents from Branch Managers to operation Managers five Banks UBL, HBL, $\mathrm{ABL}$, Askari and Alfalah Bank constrained. Unwavering quality Analysis ( $\alpha=0$ to 1 ) (Alpha = condition consistent) Reliability test was surrendered out on likert size of inquiries and which demonstrates the dependability as Chronbach $\alpha=$ 0.90 , it implies that instrument for information accumulation is $87 \%$ solid. Which ought to be $\alpha=0-1$. Though a few specialists and some books recommend, that unwavering quality of the instrument ought to be $\alpha=0.70, \alpha=0.80$ yet dependability of poll is Chronbach $\alpha=0.90, \mathrm{WHICH}$ implies survey is legitimate for information gathering.

\section{Cronbach's Alpha No.of Items}

$0.90 \quad 50$

\section{Component Analysis}

Exploratory Factor Analysis test was connected and discovered Component Matrix/Score of inquiries. In which 50 things (Questions) were entered in exploratory component examination test, then 15 question came into cross stacking, and 30 inquiries and 6 variable were concluded.

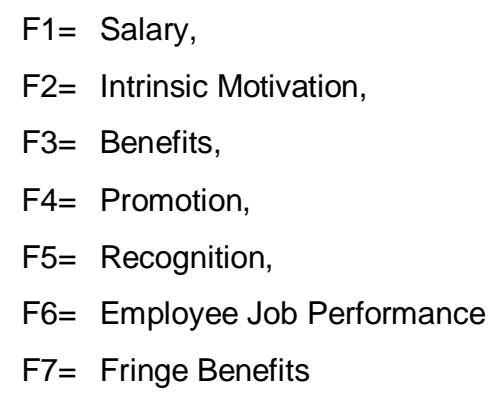


F8= Job Satisfaction

$\mathrm{F} 9=$ Job Rotation

F10= Organization culture

$\mathrm{F} 11=\quad$ Organization Environment

Table 1.3

Model Summary

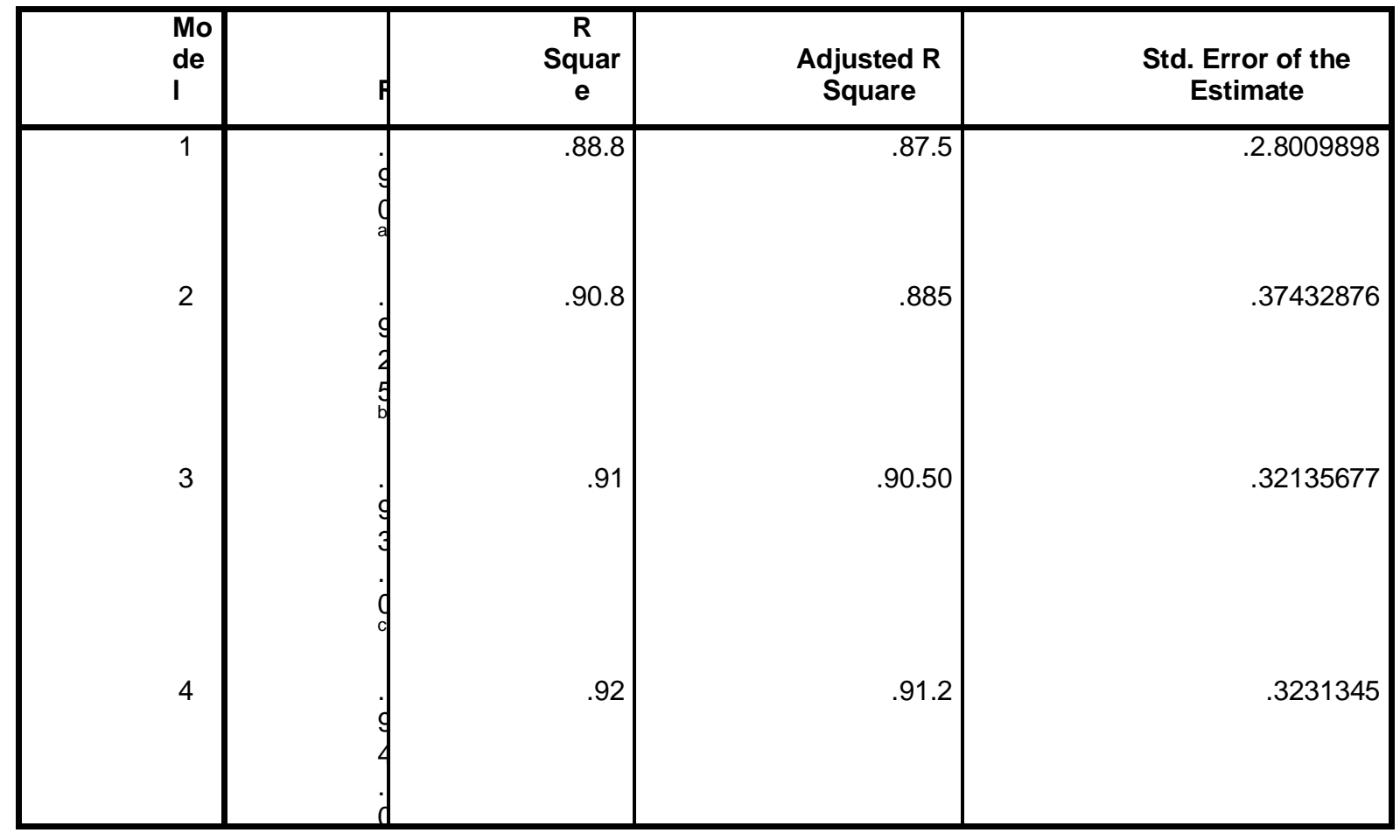

a. "Predictors: (Constant), Benefits"

b. "Predictors: (Constant), Benefits, Salary"

c. "Predictors: (Constant), Benefits, Salary, Promotion" 
Model Summary

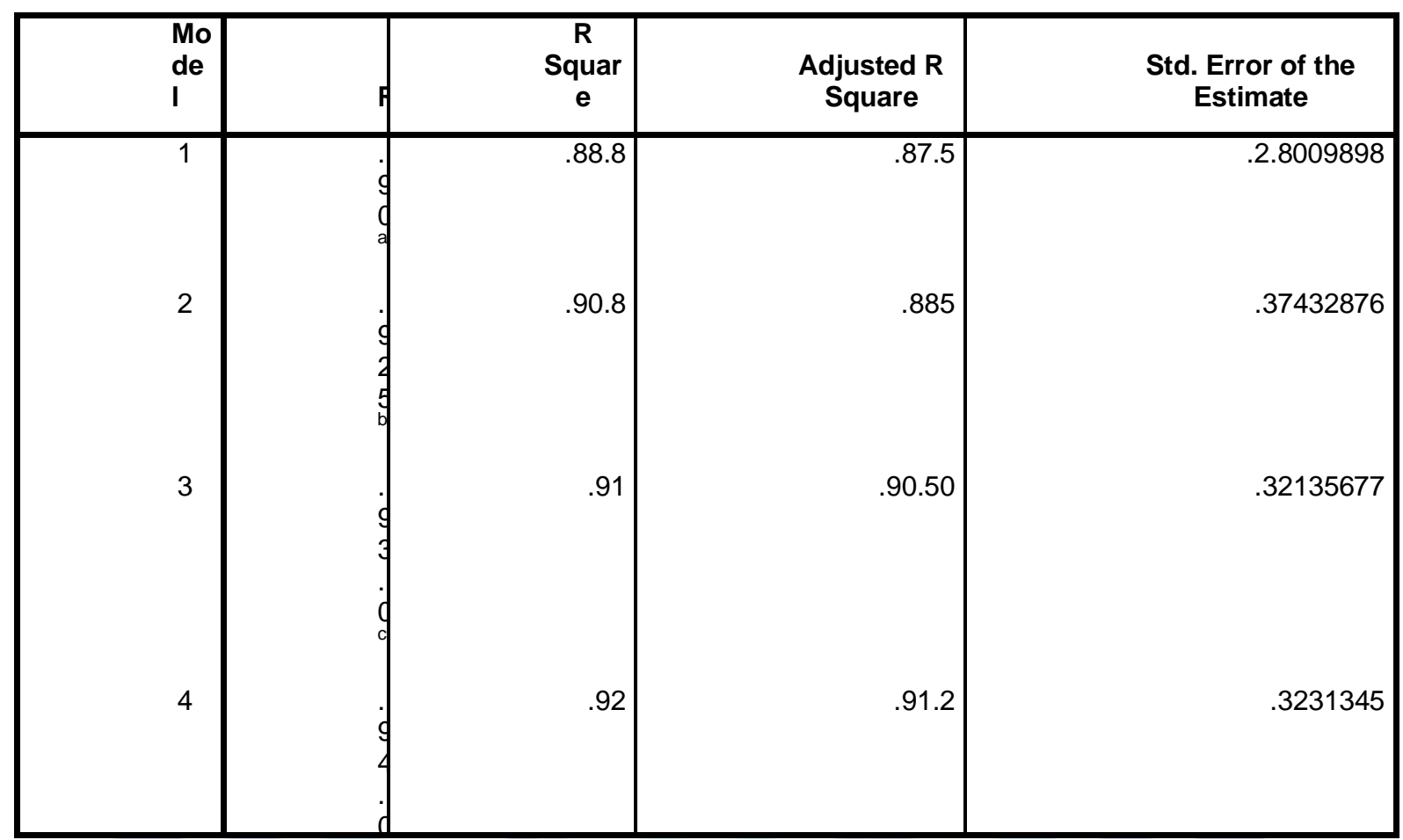
a. "Predictors: (Constant), Benefits"
b. "Predictors: (Constant), Benefits, Salary"
c. "Predictors: (Constant), Benefits, Salary, Promotion"
d. "Predictors: (Constant), Benefits, Salary, Promotion, Intrinsic Motivation"

Excluded varables

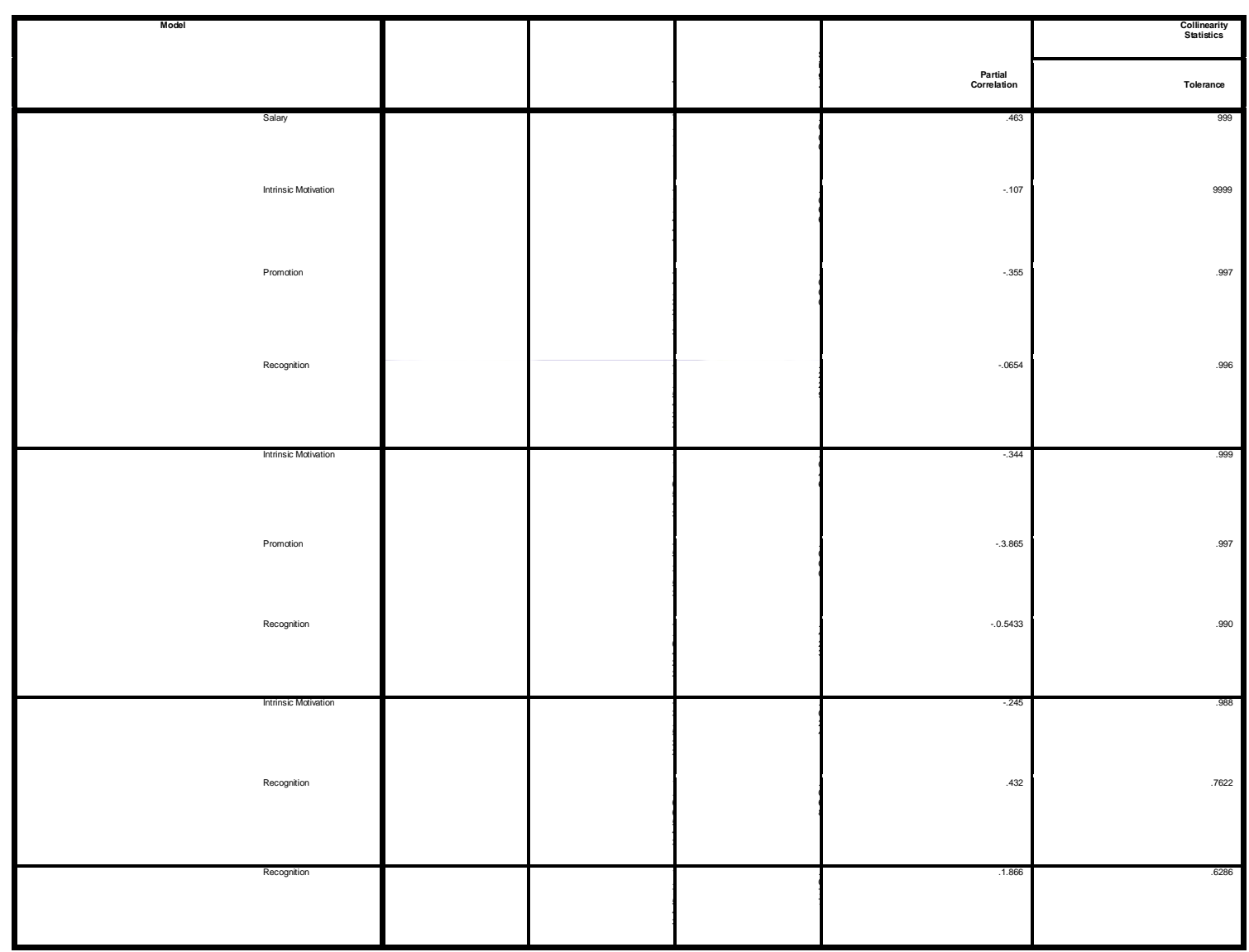




\section{Conclusions}

The current research highlighted Mainly employee performance depends upon work done by employee in any organization. Banking industry in Pakistan is very tough in terms of working hours most of the mangers are not enjoying their social life. Motivation is the only tool to give them boost for working. Development needs are the cravings to self improvement, innovativeness, development, and fitness. As per Alderfer, one might be spurred by requirements on a few levels in the meantime and when people are disappointed in meeting one level needs, they may focus on the following lower level needs. McClelland's Needs Theory of Motivation David C. McClelland separated inspiration.

\section{REFERENCES}

1.Amir B. Pirzada (2015) Assessing the Importance of Motivation on the Performance Of Employees "A Case Study Of Teaching Faculty Of Government Colleges Of Sukkur Region"

2.Agarwal, A. S. (2010). Motivation And Executive Compensation. IUP Journal Of Corporate Governance, 9(1), 27-46.

3.Borkowski, N., 2009.Organizational Behavior In Health Care.(2nd Ed.). Canada: Jones And Bartlett Publishers.

4.Daft, R.L. \&Marcic, D., 2009. Understanding Management. (6th Ed.). USA: Thompson South-Western.

5.Ahmad, F.S., Gilkar, N.H., Darzi, J.A., 2008. Organizational Behavior. New Delhi: Atlantic Publishers And Distributors.

6.Blumberg, B., Cooper, D.R., Schindler, P.S., 2008. Business Research Methods.(2nd Ed.). Berkshire: Mcgraw-Hill Education.

7.Daft, R.L., 2008. The Leadership Experience.(4th Ed.). USA: Thompson South-Western."

8.Bagraim, J., Cunningham, P., Potgieter, T. \&Viedge, C., 2007. Organizational Behavior. A Contemporary South African Perspective.(2nd Ed.). Pretoria: Van Schaik.

9.Anon, (No Date).Intrinsic/Extrinsic motivation and Hierarchy of Needs [online]. Available from: http://www2.fiu.edu/ cryan/motivation/intrinsic.htm [Accessed 16 October 2012]

10.Agarwal, A. S. (2010). Motivation And Executive Compensation. IUP Journal Of Corporate Governance, 9(1), 27-46."

11.Daft, R.L. \&Marcic, D., 2009. Understanding Management. (6th Ed.). USA: Thompson South-Western."

12.Borkowski, N., 2009.Organizational Behavior In Health Care.(2nd Ed.). Canada: Jones And Bartlett Publishers."

13.Ahmad, F.S., Gilkar, N.H., Darzi, J.A., 2008. Organizational Behavior. New Delhi: Atlantic Publishers And Distributors."

14.Blumberg, B., Cooper, D.R., Schindler, P.S., 2008. Business Research Methods.(2nd Ed.). Berkshire: Mcgraw-Hill Education".

15.Daft, R.L., 2008. The Leadership Experience.(4th Ed.). USA: Thompson South-Western."

16.Bagraim, J., Cunningham, P., Potgieter, T. \&Viedge, C., 2007. Organizational Behavior. A Contemporary South African Perspective.(2nd Ed.). Pretoria: Van Schaik

17.Coetsee, L.D., 2003. Peak Performance And Productivity. (2nd Ed.). Potchefstroom: VaSchaik."

18.Collis, J. \& Hussey, R., 2003. Business Research. (2nd Ed.). NY: Palgrave Macmillan."

19.Cronje, G.J., Du Toit, G.S. \&Motlatla, M.D.C., 2000. Introduction To Business Management. Cape Town: Oxford University Press Southern Africa".

20.Deci, E. L. \& Ryan, R. M. (2008). Facilitating optimal motivation and psychological well-being across life's domains. Canadian Psychology, 49. 14-23.

21.Buitenlandse, Z. (2008). Primary education in Uganda.JOB impact evaluation, Policy and operations evaluation department, No. 311. 